\title{
Núcleo de Estudos Sobre Marcadores Sociais da Diferença (NUMAS)
}

Inaugurado em 2007, o Núcleo de Estudos Sobre Marcadores Sociais da Diferença (NUMAS) foi idealizado por um grupo de professores e alunos de graduação, pós-graduação e pesquisadores de pós-doutorado vinculados ao Departamento de Antropologia da Faculdade de Filosofia, Letras e Ciências Humanas da Universidade de São Paulo (USP), que vinha se reunindo com o objetivo de partilhar ideias e trocar experiências de pesquisa envolvendo a produção social da diferença por meio da articulação de categorias de raça, gênero, sexo, idade e classe, tanto do ponto de vista da configuração de sistemas de classificação social quanto da constituição de corpos e identidades coletivas. Percebia-se, desde então, que temas anteriormente tratados de maneira separada como problemas teóricos estanques precisavam ser compreendidos e estudados em suas intersecçóes.

O Brasil, como outros países, vem assistindo nos últimos anos a uma discussão pública crescente sobre questão "racial" e "racismo", miscigenação e nação, sistema de ação afirmativa, cotas e políticas públicas com base na diferenciação por "cor/raça”, além da reconfiguração da questão das terras ditas "terras de pretos" ou dos "remanescentes dos quilombos". No âmbito das questóes relacionadas à sexualidade e ao gênero, vivemos também um processo de importantes redefiniçóes, tanto no nível da ética sexual (os limites do que deve ou não ser tolerado), quanto no nível da política sexual propriamente dita (os limites do que deve ou não ser criminalizado). As discussões em curso no país sobre o casamento entre pessoas do mesmo sexo, o combate à violência conjugal e ao assédio sexual, o aborto assistido, a profis- sionalização da prostituição e o turismo sexual são apenas alguns exemplos desse processo de transformação.

Problemas sociais e problemas de pesquisa sócio-antropológica especificam-se crescentemente em sujeitos de direitos minoritários referidos a marcadores de raça, etnia, gênero e orientação sexual, que passam a ocupar de modo inédito a agenda política e acadêmica do país. Ao se penetrar no labirinto da produção de categorias identitárias e formas de discriminação associadas àqueles marcadores de diferença, é possível perceber como a produção do saber vem atuando e sendo incorporada aos movimentos sociais em questão.

Trata-se, portanto, não apenas de reelaborar questôes clássicas e recorrentes sobre miscigenação, erotismo e nação, mas também refletir sobre o impacto das políticas de identidade e de açóes afirmativas, percorrer o embate entre políticas de escopo universalista e políticas de promoção de direitos especiais, bem como buscar a compreensão renovada de convençóes, representaçóes e sociabilidades associadas a raça, etnia, religião, deficiência, sexualidade e gênero. Os novos tempos trazem novos desafios conceituais e acabam por exigir igualmente novas frentes de pesquisa, evidenciando a necessidade de lançar mão de perspectivas mais comparadas, que inter-relacionem aquelas categorias e redimensionem sua própria aplicabilidade e significação.

Nesse sentido, o NUMAS, com apoio de agências financiadoras como a FAPESP, CNPq, CAPES, Fundação Ford e a própria USP, vem desenvolvendo várias linhas de atuação acadêmica, dentre as quais se destacam: 
350 | Núcleo de Estudos Sobre Marcadores Sociais da Diferença (NUMAS)

- A produção histórica e cultural da racialização/etnização da sexualidade e da sexualização da raça/etnia, e suas implicaçóes em termos dos diferentes sistemas de dominação.

- A articulação de gênero e sexualidade em corpos hierarquizados em termos de raça/etnia e classe.

- Imagens, representações, convençóes e saberes em torno de raça, etnia, religião, deficiência, sexualidade, gênero e idade/geração

- Práticas cotidianas e sociabilidades em torno de raça, etnia, religião, deficiência, sexualidade, gênero e idade/geração

- Políticas e discursos públicos sobre raça, etnia, religiáo, deficiência, sexualidade, gênero e idade/geração.

- Produção de desigualdades em torno destas categorias e de suas intersecçóes

- Interações entre racismo, sexismo, homofobia, discriminação etária, intolerância religiosa e as formas de naturalização e essencialização de diferenças sociais.

Tendo em vista tais debates, desde 2008 o NUMAS participa da realização de uma série de eventos, de caráter ampliado, com participantes convidados do país e do exterior voltados ao diálogo com suas propostas e à divulgação das pesquisas realizadas pelos docentes. Em 2011, estudantes de pós-graduação vinculados ao núcleo passaram a promover encontros regulares em que tiveram a oportunidade de discutir mais detalhadamente seus trabalhos, tanto com professores do próprio núcleo quanto com convidados de outras instituiçóes. Essa proposta foi acolhida com entusiasmo por alunos e docentes e continua sendo posta em prática com o apoio de novos integrantes.
Blog: www.numas-usp.blogspot.com

Facebook: https://www.facebook. com/pages/NUMAS - N\%C3\%BAcleo-de-Estudos-sobre-Marcadores-Sociais-da-Diferen\%C3\%A7a/162429853825580

Contato: numas.usp@gmail.com

Professores responsáveis: Julio Assis Simões, Lilia Schwarcz, Laura Moutinho, Heloisa Buarque de Almeida e Vagner Gonçalves da Silva

Pós-doutorandos: Wagner Lins, Mariana Leal de Barros, Antonio Giovanni Boaes Gonçalves, Estrella Maestre Amigo, Rocío Alonso Lorenzo

Doutorandos: Gustavo Santa Roza Saggese, Ramon Pereira Reis, Gleicy Silva, Paulo Dantas, Rafael Noleto, Thiago Lima de Brum, Eduardo Dimitrov, Luiz Felipe Kojima Hirano, Leonardo Bertolossi, Rebeca Campos Ferreira, Rosenilton Silva de Oliveira

Mestrandos e Mestres: Marisol Marini, Natália Lago, Pedro Lopes, Marcio Zamboni, Ane Talita Rocha, Michele Escoura Bueno, Renata Mourão Macedo, Beatriz Accioly Lins, Marcella Betti, Valéria Alves, Bernardo Machado, Bruna de Carvalho Lima, Tatiana Lotierzo, Marina Barbosa e Silva, Patricia Ferreira e Silva, Milton Bortoleto

Graduandos: Rafael do Nascimento Cesar, Crisliane Falchetti, Fernanda Kalianny Martins Souza, Izabela Nalio Ramos, Renata Harumi Cortez Toma, Marina Macedo Rego, Nrishinro Vallabha Das Mahe, Roberta Heleno Novello, Alcides Moreno, Luiza Ferreira, Thais Tiriba, Eros Sester Guimarães, Anouch Kurkdjiam, Taína Mansani, Álvaro Russo Junior 